\title{
Self-construals, Symbolic and Hedonic Preferences, and Actual Purchase Behavior
}

Article

Accepted Version

Millan, E. and Reynolds, J. (2014) Self-construals, Symbolic and Hedonic Preferences, and Actual Purchase Behavior. Journal of Retailing and Consumer Services, 21 (4). pp. 550560. ISSN 0969-6989 doi:

https://doi.org/10.1016/j.jretconser.2014.03.012 Available at https://centaur.reading.ac.uk/38122/

It is advisable to refer to the publisher's version if you intend to cite from the work. See Guidance on citing.

Published version at: http://www.elsevier.com/locate/jretconser

To link to this article DOI: http://dx.doi.org/10.1016/j.jretconser.2014.03.012

Publisher: Elsevier

All outputs in CentAUR are protected by Intellectual Property Rights law, including copyright law. Copyright and IPR is retained by the creators or other copyright holders. Terms and conditions for use of this material are defined in the End User Agreement.

www.reading.ac.uk/centaur 
Central Archive at the University of Reading

Reading's research outputs online 


\title{
Self-construals, Symbolic and Hedonic Preferences, and Actual Purchase Behavior
}

\author{
Elena Millan \\ Department of Food Economics and Marketing, University of Reading, Earley Gate, \\ Whiteknights Road, Reading, RG6 6AR, United Kingdom

\section{Jonathan Reynolds} \\ Saïd Business School, University of Oxford, Park End Street, Oxford, OX1 1HP, \\ United Kingdom
}

\begin{abstract}
Published in the Journal of Retailing and Consumer Services (2014), http://dx.doi.org/10.1016/j.jretconser.2014.03.012i
\end{abstract}

\begin{abstract}
The study explores the influence of the independent and interdependent self-construals on actual purchase behavior and the mediating role of consumer preferences for symbolic and hedonic meanings. Data were collected through a survey of about 1,000 respondents. Results indicate that independent consumers draw on the self/hedonic- and status-symbolic resources of clothing in the construction and expression of their identities. Regarding the interdependent consumers, they show no interest in clothing affiliation and status symbolism. The degree of preference for status-symbolic meaning mediates all effects of the independent and interdependent self-construals on actual purchase behavior; self-expressive/hedonic preferences mediate two of the three effects of the independent self on actual purchase behavior when accounting for suppression effects, whereas the expected mediation of preference for affiliation meaning is not supported.
\end{abstract}

Keywords: Independent and interdependent self-construals; Symbolic and hedonic preferences; Actual purchase behavior 


\section{Introduction}

The independent and interdependent self-construals are central aspects of one's selfdefinition, which have significant bearing on human cognition, emotion, motivation and individual experiences (Markus \& Kitayama, 1991). As such, these influences are likely to extend to the consumption sphere. More recently, consumer research has examined issues such as the interactions between one's dominant independent or interdependent self-construal and advertising appeal types (i.e. individualist or collectivist), and their influence on brand attitudes (e.g. Aaker \& Schmitt, 2001), brand evaluations (Agrawal \& Maheswaran, 2005), and attitude toward the ad (Wang \& Mowen, 1997). The concept of the self occupies a prominent place in the symbolic consumption literature, according to which people draw from the symbolic resources of goods to construct, express, and enhance their identity (Elliott, 1997). However, many of the existing studies in this particular strand of research conceptualize the self as an all encompassing entity, whereas its constituent parts are often overlooked, thus obscuring the relationships between salient aspects of the self and one's possessions (Kleine, III., Kleine, \& Kernan, 1993). Given the importance of one's independent or interdependent tendencies in their self-definition and the central role of symbolic and hedonic considerations in contemporary consumers' choices, studying the effects of the former on individual preferences for self- and social-symbolic meanings of consumption artifacts is particularly worthwhile. What is more, independent individuals' emphasis on uniqueness and autonomy tends to be more consistent with greater attentiveness to the self-symbolic meaning of clothing artifacts, whereas interdependent individuals' emphasis on acceptance and fitting in to be more consistent with a stronger preference for clothing affiliation symbolism. While support for these ideas have been found (Lee \& Kacen, 2000), the theoretical explanations regarding the possible effects of the independent and interdependent self-construals on status consumption are contradictory, and so are the 
findings of the limited research conducted to-date (see Millan \& Reynolds, 2011; Kastanakis \& Balabanis, 2012). In addition, according to Lee and Kacen's (2000) findings, interdependent individuals may also be motivated by uniqueness reasons in their purchase behavior. As this is a single study reporting such an unexpected relationship, its validity needs to be further examined. What is more, if this finding were not due to chance, given that expression of distinct self-attributes runs counter to the collectivist ethos, why would interdependent consumers be willing to engage in such behavior? This question is yet to be answered.

Another interesting issue that remains largely unexplored is whether, how, and to what extent the independent/interdependent self-construals affect actual purchase behavior. Do behavioral outcomes such as frequency of visits to clothing shops to see the new arrivals and money spent on clothing change if an independent or interdependent self-construal is more dominant? In view of the centrality of the independent or interdependent self-construal in one's self-definition and their motivational power, this question needs to be clearly answered. In addition, are the effects of these more general self-construals likely to be mediated by specific consumer-related preferences for self and/or social-symbolic meanings of clothing? An exploration of the simultaneous interactions among the independent/interdependent selfconstruals, product/brand meanings' preferences, and actual purchase behavior will advance our understanding of the mechanisms through which these important self-construals affect people's behavior in the marketplace, and thus will be of considerable value to both researchers and marketers. The high potential of this dual self-construal for marketing practice is indicated by its significant bearing on consumer attitudes toward brands and the persuasiveness of advertising appeals (e.g. Aaker \& Schmitt, 2001), as well as its ability to identify viable consumer segments (Millan \& Reynolds, 2011). 
As apparent from the above discussion, the present study explores the effects of the independent and interdependent self-construals in the context of clothing purchase behavior. The clothing product category was chosen because of its particular relevance to the selfconcept and the symbolic/hedonic aspects of consumption. Due to their value-expressive and image-enhancing capacities, clothing artifacts are often used to construct, express and enhance one's self-concept. Additionally, people are often judged by others on the basis of their appearance and their attire in particular (e.g. Howlett, Pine, Orakçioglu, \& Fletcher, 2013).

To sum up, this study pursues the following objectives: first, to develop a conceptual model of the effects of the independent and interdependent self-construals on actual purchase behavior (i.e. frequency of clothing shops' visits to check for new arrivals, frequency of clothing purchases, and amount of money spent on clothing) and to test its validity with a nationally representative sample drawn in the Czech Republic; and second, to establish the mediating role of consumer preferences for self-expressive/hedonic and status meanings of clothing artifacts on some of these relationships. By addressing these issues, this study advances our understanding of the psychological processes underlying consumer decisions and actual purchase behavior regarding clothing artifacts. It also develops further the framework within which symbolic and hedonic consumption has been studied to date by considering, for the first time, both the direct and the mediated effects of two distinct yet central aspects of the self. The study's findings can also be of value to a broader range of publicly consumed value-expressive product categories, such as mobile phones, watches, footwear and accessories. A further contribution to marketing science is related to the location in which the present study was conducted. Specifically, by testing the proposed conceptual model in the Czech Republic, a former socialist country which embarked on market reforms in 1989, the usefulness and generalizability of the theories on which the 
model is based to other national and cultural settings can be established. Last but not least, a number of managerial and research implications are drawn from the study's findings.

\section{Theoretical framework}

\subsection{Independent and interdependent self-construals}

The independent self-construal is a distinctive configuration of inner traits, thoughts and feelings that regulate individual behavior and underlie individual strivings toward the fulfillment of self-centered tasks, such as assertion, expression and actualization of one's unique self, and promotion of own goals. The independent self-construal emphasizes the individual's motives, goals, attitudes, inner feelings, and behaviors. It is bounded, unitary, stable, autonomous, self-determined, individualist, egocentric, self-contained, separate, and largely detached from the social context in which it occurs (Markus and Kitayama, 1991). This relatively stable configuration of attributes and traits finds expression in behavior, which tends to be consistent across different situations (De Mooij, 2010). Self-esteem derives mainly from one's ability to express self and validate internal attributes, as well as from the assessment of self-directed accomplishments (see Kwan, Bond, \& Singelis, 1997).

In contrast, the interdependent self-construal has been defined as "seeing oneself as part of an encompassing relationship and recognizing that one's behavior is determined, contingent on and, to a large extent, organized by what the actor perceives to be the thoughts, feelings, and actions of others in the relationship" (Markus \& Kitayama, 1991, p. 227). People with a strong interdependent self-construal emphasize social roles and relationships, belonging and fitting to the in-group (e.g. extended family, friends, and neighbors), occupying one's proper place and engaging in appropriate behavior (Markus \& Kitayama, 1991; Singelis, 1994). The interdependent self-construal is intimately related to its social environment, is dependent on others, and is highly responsive to contextual influences (Singelis \& Brown, 1995). By 
attending and adjusting behavioral responses to contextual clues, the interdependents gain approval and maintain harmonious relationships (Aaker, 1999), which form the basis of their positive self-regard (Markus \& Kitayama, 1991).

A person's identity accommodates two contradictory tendencies of interdependence and independence (Brewer \& Gardner, 1996). The strength and manifestation of one's independent or interdependent self is a consequence of the particularities of the cultural environment (e.g. homogeneous or heterogeneous cultures), one's cultural background, and specific situational factors (Trafimow, Triandis, \& Goto, 1991; Triandis, 1993). In general, self-views developed in individualistic cultural systems, which emphasize individualcentered values such as achievement of personal success, self-direction, hedonism, and stimulation (Schwartz \& Bardi, 2001), tend to be more independent, and this self-construal becomes chronically accessible. Conversely, for individuals brought up in collectivist societies, which emphasize group-centered values such as a sense of belonging, harmony and solidarity with others, respect to parents, elders and superiors, obedience, respect for traditions, moderation, thrift, and modesty (see Chinese Culture Connection, 1987; Schwartz, 1994), it is the interdependent self that becomes chronically accessible (Singelis, Bond, Sharkey, \& Lai, 1999).

\subsection{Symbolic and hedonic consumption}

Symbolic consumption is the acquisition of products and brands not for their functional benefits but for the culturally shared and idiosyncratic meanings they convey to others and the society. Thus, it is an act of communication between the consumer and other members of a society, as well as between the consumer and his/her self (Noth, 1988). Consumption products act as signs that represent something beyond their tangible attributes through interpretation or emotion (Csikszentmihalyi \& Rochberg-Halton, 1981). In today’s 
marketplace most brands, even low-involvement ones, are promoted with image-oriented promotional messages. Social exchanges, cultural practices, and marketers' activities mold and reinforce the public meanings of goods (Richins, 1994a). Consumers use these consumption symbols creatively in constructing individual meanings pertinent to their identities, life circumstances and aspirations (Elliott \& Wattanasuwan, 1998). Diverse meanings can be ascribed to consumption objects. Csikszentmihalyi and Rochberg-Halton (1981, p. 27) argue that objects are signs of the qualities of the self, of one's ways of being, feeling, and living. Objects as signifiers of our identities perform three functions: first, they reflect and create our sense of self; second, they are signs of individual power and status; and third, they can stand for social integration and individual differentiation. Drawing on previous studies and her own research, Richins (1994b) identifies four categories of product meanings: utilitarian, enjoyment, presentations of interpersonal ties, and identity and self-expression. Utilitarian meaning relates to products' usefulness derived from their tangible attributes (e.g. Sheth, Newman, \& Gross, 1991). Enjoyment is associated with products' capacities to evoke pleasurable experiences during consumption, such as "fun, amusement, fantasy, arousal, sensory stimulation, and enjoyment" (Holbrook \& Hirschman, 1982, p.135), and aesthetic contemplation and gratification (e.g. Kleine, Kleine, III \& Allen, 1995). Products also symbolize social relationships such as those with loved ones (e.g. Hirschman \& LaBarbera, 1990; Noble \& Walker, 1997). One's self-concept may be defined through affiliation with important others by emulation of the consumption patterns and lifestyles of membership or aspirational groups (e.g. Kleine, et al., 1995). In addition, possessions function as symbols of one's position in the societal hierarchy (e.g. Carr \& Vignoles, 2011). Furthermore, consumption objects signifying status and prestige have the potential to empower and enhance one's self-concept (Dubois \& Duquesne, 1993). As vehicles for self-expression, possessions symbolize unique personal qualities and value systems, as well as reflect 
personal history (Dittmar, 1992, p. 89). As contributors to and reflection of our identities, our possessions become incorporated into our self-concepts (Belk, 1988).

Clothing artifacts can convey a constellation of meanings both to owners and observers, some of which may be widely shared, while others may be idiosyncratic, pertinent only to the wearer's identity. Previous studies have shown that clothing artifacts are a potent means for constructing and expressing aspects of one's identity, and this dynamic self-expressive process can engender pleasurable experiences (e.g. Guy \& Banim, 2000). During purchase and use, specific garment features such as style, color, fit, workmanship and fabric quality can stimulate our senses and imagination. This sensory input coupled with others' reactions to our appearance has a significant bearing on our emotional states (see Banim, Green, \& Guy, 2001). Clothing symbolism is also used to nurture affiliation with and fitting in social groups (e.g. Piaceniti \& Mailer, 2004), to demarcate class and status boundaries and to facilitate upward social mobility (Crane, 2000; Veblen, 1899).

\subsection{Hypotheses}

The conceptual model with the study hypotheses is presented in Figure 1. The discussion below leading to the development of hypotheses $\mathrm{H} 1$ and $\mathrm{H} 2$ is based on the recent arguments of mediation effects (e.g. Hayes, 2009; Zhao, Lynch, \& Chen 2010; Rucker, Preacher, Tormala, \& Petty, 2011), according to which a significant indirect effect $a$ x $b$ established by a bootstrap test is sufficient to demonstrate mediation. Building on a critical appraisal of Baron and Kenny's (1986) frequently used treatment of mediation analysis, the adopted in our study mediation offers new insights for advancing theory development and testing. The effects of the gender covariate, the direct effects of the independent and interdependent selfconstruals, as well as the effects of preference for affiliation symbolism on frequency of clothing shops' visits to see the new arrivals, frequency of clothing purchases, and money spent on 
clothing, are also estimated in the structural equation model. For clarity of presentation, they are not shown in the figure.

[Figure 1 here]

\subsubsection{Independent self-construal, preference for self-expressive and hedonic meanings, and} actual purchase behavior

This study hypothesizes that the independent self-construal will have a positive effect on preference for the self-expressive and hedonic meanings of clothing, which in turn will result in a higher frequency of clothing shops' visits and of purchases, as well as in more money spent on clothing artifacts. The rationale for these relationships comes mainly from Markus and Kitayma's (1991) self-construal theory. As discussed above, independent individuals highly value their uniqueness, which underlies their motivation to demonstrate their difference from others (Aaker \& Lee, 2001). Behaving differently from others engenders positive feelings in such individuals, who maintain a positive self-regard by performing tasks associated with the expression of unique inner attributes (Markus \& Kitayama, 1991). These tendencies are reinforced in contemporary Western societies, in which expressions of independence, uniqueness and self-determination, including those achieved through individual consumption practices, are highly valued (Aaker \& Schmitt, 2001).

In addition, according to the self-image/product-image congruity theory (Sirgy, 1982), consumers particularly value those products and brands the image attributes of which are congruent with their own self-image. In other words, the product or brand is used as a symbolic resource for self-expression. A person's self-concept generally comprises positive personality traits, and their expression elicits positive feelings (e.g. pleasure or pride), whereas inability for self-expression brings about negative affect (e.g. disappointment or dissatisfaction) (Aaker, 1999). Given the positivity of independents' self-views and their 
motivation to express individuality and difference, they are likely to use products and brands to present a unique self-image to others. Indeed, in a qualitative inquiry, Thompson and Haytko (1997) find that fashion discourses are used to construct and preserve a sense of distinctive personal identity through the uniqueness of consumption choices. Similarly, Lee and Kacen (2000) report positive associations of a person's independent self-construal with purchase reasons related to unique features/styling for both impulse and planned purchases.

The self-expressive process involves not only self-schema traits, but also self-focused emotions. Markus and Kitayma (1991) argue that independent individuals attend more to their inner feelings and act upon them to a greater extent than interdependent individuals. In line with this logic, Oishi et al. (1998) report that stimulation is among the value priorities of individuals with dominant independent self-construals. In addition, the self-regulatory focus of independent individuals is on approaching pleasure rather than avoiding pain (Aaker \& Lee, 2001). Evidence suggests that these notions apply also to the consumption sphere (e.g. Dutta-Bergman \& Wells, 2002). From a sociological standpoint, given that the independent self is largely detached from the social context, extended family and other stable social networks, independents may be lonely at times, at best, or isolated at worst. The self-reliant, autonomous independent individual typically lacks the emotional and other support from close-knit communities. By contrast, interdependent individuals provide emotional, financial, and other support to group members-there is a strong sense of camaraderie, loyalty, support, and joint responsibility for protecting group members and their well-being. Hedonic consumption can be, and is often, used to regulate individual emotional states. What is more, it is within easy reach. Thus, consumers with a dominant independent self-construal may show a stronger preference for goods that can engender sensory stimulation and emotional gratification. 
Regarding the relationship between preference for self-expressive symbolism and actual purchase behavior, it is hypothesized here that such preference will result in more frequent visits to clothing shops to see whether they have received something new, more frequent purchases of clothes for oneself, and more money spent on clothing. The construction and expression of the project of the self is a lasting process (Giddens, 1992), involving continual use of new and varied symbolic resources preferably possessed by just a handful of consumers. Hence, a wardrobe with more and varied clothing items may be needed to fulfill the self-expressive goal. In line with this notion, an emphasis on uniqueness and selfexpression is reported to drive variety-seeking tendencies (Kim \& Drolet, 2003) and stronger desires for high-variety product assortments (Herrmann \& Heitmann, 2006). What is more, changes in the consumption context often require the expression of different aspects of the self. For example, in a work environment one's attire can, and is typically used to, project a professional image, whereas in leisure setting a different aspect of the self (e.g. one's feminine or sporty side) may be more strongly emphasized. Consumers' desire for yet another, more novel and appealing, way for self-expression through consumption may become chronically aroused as a result of the speed with which new fashions are introduced nowadays and consumers' increased exposure to them, especially through the Internet (24 hours a day, 7 days a week) and its online social media applications (e.g. Facebook), as well as through the growing use mobile digital devices (e.g. smartphones) and their shoppingrelated apps (see Sterling, 2012). The ever easier and more secure way to order online without time or geographic barriers and the private nature of the online shopping environment, largely devoid of important others' controls and personal inhibitions (see Rose \& Dhandayudham, 2014), facilitate further the fulfillment of such desires.

The hedonic value of material objects in general, and of clothing in particular, tends to decline as they lose their novelty. During use, as consumers become increasingly accustomed 
to their possessions, the latter cease to provide as much pleasure and stimulation. In addition, marketers are quite skilled at introducing new and yet more alluring versions of their products, stirring fantasies and promising new experiences that are too tempting to be missed out. Such stimuli can arouse strong desires for immediate possession of the hedonically rewarding new clothing fashions. Furthermore, clothing retail environments are designed to provide intense sensory stimulation and engender further pleasurable experiences during the shopping trip (e.g. Arnold \& Reynolds, 2003). Thus, preference for hedonic experiences with clothing artifacts may lead to more frequent visits to clothing shops, more frequent purchases, and spending more money on clothing. Therefore, the following hypothesis is proposed:

H1: The effect of the independent self-construal on (a) frequency of visits to clothing shops to see the new arrivals, (b) frequency of clothing purchases, and (c) money spent on clothing will be mediated by preference for self-expressive/hedonic meanings of clothing.

\subsubsection{Independent/interdependent self-construals, preference for status meaning, and actual} purchase behavior

As argued above, independent individuals place a high value on being unique and different from others. The expression of this individuality can be achieved through, for example, the consumption of expensive and/or scarce luxury goods, which many others may not be able to afford (Tepper \& Hoyle, 1996). Mason (1992) argues that the need for distinctiveness is one of the motivating factors for status consumption. In addition, independent individuals tend to be guided in their lives by ambition and personal achievement (see Schwartz, 1994). Personal success is not only a source of self-esteem for independents, it is also an important means of gaining higher status and thus further freedom and independence (see Clark, Zboja, \& 
Goldsmith, 2007). Thus, those with dominant independent self-construals are likely to be more concerned with their status in society. Consistent with this logic, evidence suggests that higher-status individuals tend to have stronger independent selves, whereas lower-status individuals are more cooperative and communal (e.g. Lee \& Tiedens, 2001). Thus, the independent self-construal is likely to be positively related to preference for clothing status symbolism. This notion is supported by Clark et al. (2007) and Millan and Reynolds (2011), although it is at odds with Kastanakis and Balabanis' (2012) finding of a negative effect of the independent self-construal on status consumption.

It is also anticipated here that consumers who prefer up-market attire will be more active shoppers. More frequent visits to clothing shops are likely to be motivated by a drive to keep updated about the new arrivals and latest fashion trends. Latest fashions can confer status and prestige to their wearers due to their newness, uniqueness, and high price tags. Their ownership also conveys a message about the financial ability to update one's wardrobe nearly every fashion season. It has been argued that social status is often the main motivator for, and the sole benefit of, the early adoption of new clothing fashions (Briley, 2009; Rogers, 2003). Besides, the novelty of owned clothes wears out with every public appearance. What is more, as mentioned above, nowadays new clothing fashions are introduced more often then ever before. As a result, a stronger preference for clothing status symbolism may result in more frequent clothing purchases. Also, an inherent characteristic of status clothing brands is their premium pricing. Indeed, higher prices of socially visible brands typically result into more status buying (Chao \& Schor, 1998). Thus, consumers' interest in clothing status symbolism is likely to translate into more money spent on clothing. Therefore, the following hypothesis is proposed: 
H2: The effect of the independent self-construal on (a) frequency of visits to clothing shops to see the new arrivals, (b) frequency of clothing purchases, and (c) money spent on clothing will be mediated by preference for status meaning of clothing.

Theoretical postulates and empirical evidence are ambiguous regarding the interaction between the interdependent self-construal and status consumption. As argued above, interdependent individuals derive self-esteem from harmonious and fulfilling relationships. Actions that disrupt social harmony tend to be avoided. An individual's striving for status has the potential to challenge harmony and solidarity of in-group relationships. As Layard (1980, p. 738) states, "If status is defined by rank order, the pursuit of status is a zero-sum gameone man's gain in rank is another man's loss." What is more, possession of status markers may suggest that the individual has or is seeking a different position relative to the other ingroup members, and this may result in group disapproval and rejection. Another argument relates to the values endorsed by interdependent individuals, such as thrift, frugality, modesty, humility, non-competitiveness, and 'following the middle way' (see Gao, 1996; Oishi, et al., 1998). Status consumption is clearly not compatible with such values. For the interdependent individual, choosing a piece of clothing that everybody else wears may not be a sign of social dishonor, but a marker of wisdom and collectivist ethos, a way of aligning oneself with important others (Dutton, 1998, p. 275). These values may be further reinforced by deeply entrenched culturally conditioned habits of utilitarian consumption (Lim \& Ang, 2008). Furthermore, expenditures on status goods to fulfill individual status strivings can diminish the household budget allocated to the achievement of in-group goals (Lee, 2000). Such behavior runs against the collectivist philosophy. Therefore, in general those with stronger interdependent self-views may lack or have a negative interest in status 
consumption. Consistent with this logic, Millan and Reynolds (2011) find no relationship between the interdependent self-construal and preference for clothing status symbolism.

Contrary to the above thesis, commercial statistics show that Japan and China-two collectivist cultures - rank very highly in their spending on luxury goods (Schwarz \& Wong, 2006). The growth of the aspirational consumer segment (especially in emerging Asian markets) and evolving values and consumption goals prompted by rapid economic change and growing affluence, are among the main drivers of such luxury consumption (Wong \& Ahuvia, 1998). According to a relatively recent study (Microsoft, 2009), Asian consumers primarily seek status followed by quality benefits from up-market brands, whereas they place no importance on exclusivity or indulgence. A need to bond with family and friends (Schwarz \& Wong, 2006) and social pressures to conform to others' expectations to preserve one's 'face' (Wong \& Ahuvia, 1998) seem to accelerate luxury purchases in this region.

Given these controversies, a directional hypothesis cannot be advanced regarding the effect of the interdependent self-construal on preference for clothing status symbolism, nor about the possible mediating role of the latter construct on actual purchase behavior.

\subsubsection{Interdependent self-construal and preference for affiliation meaning}

The above discussion indicates that interdependent individuals are intimately connected to their social context. Relationships and important social groups shape their thoughts, feelings and behavioral responses, and they derive much of their self-esteem from establishing fulfilling harmonious relationships with close others (Markus \& Kitayama, 1991). The influence of self-defining others is likely to be transferred to the consumption sphere. Indeed, some consumer studies report that advertising appeals emphasizing in-group (e.g. family, friends) benefits are more persuasive and tend to elicit more positive brand attitudes (e.g. Aaker \& Schmitt, 2001; Wang, Bristol, Mowen, \& Chakraborty, 2000), brand evaluations 
(Agrawal \& Maheswaran, 2005), and attitude toward the ad (Wang \& Mowen, 1997) in individuals with chronically accessible interdependent than independent self-views. In addition, Millan and Reynolds (2011) find that being interdependent relates positively to preference for affiliation meaning of clothing. Similarly, Lee and Kacen (2000) report that interdependent self-views are positively associated with group affiliation reasons for buying goods in both impulse and planned purchase scenarios, whereas the independent selfconstrual is unrelated to this phenomenon in either of the two scenarios. As to the possible mediating role of preference for affiliation symbolism, there is neither theoretical rationale nor empirical evidence to suggest how this construct may relate to actual purchase behavior; thus, it is hard to justify a test of mediation of preference for affiliation meaning on the effect of the interdependent self-construal on actual purchase behavior. In view of this, the following hypothesis is proposed:

H3: The interdependent self-construal will have a positive effect on preference for affiliation meaning of clothing.

\subsubsection{Gender covariate}

Previous research shows that women tend to have a stronger interdependent self whereas men to have a stronger independent self (e.g. Cross \& Madson, 1997; Wang, et al., 2000). These findings are in accord with the notion that women's sense of femaleness is commonly associated with communal tendencies and traits such as caring, nurturance, considerateness, and focus on shared goals. Conversely, men's sense of maleness is commonly associated with agentic tendencies and traits such as assertiveness, competitiveness, performance, and focus on individual goals, achievement, and material success (Palan, 2001). What is more, ample evidence suggests that men and women have different views and behaviors toward clothes 
shopping. For example, women are more interested in and involved with clothing than men (e.g. O'Cass, 2004; Peluchette, Karl, \& Rust, 2006). Additionally, women tend to be earlier adopters, whereas men to be later adopters of new fashions (e.g. Beaudoin, Lachance, \& Robitaille, 2003). Women feel stronger urges to buy new clothes more often than men do (Coskuner \& Sandikci, 2004), shop more often for clothes (Chen-Yu \& Seock, 2002; Mintel, 2010), and spend more on apparel than men (e.g. Mintel, 2011; Peluchette, et al., 2006). Although there are no firm grounds as to how gender may relate to clothing's symbolic preferences, women's stronger involvement with clothing, as well as their more developed skills in decoding clothing messages (Auty \& Elliott, 1998; McCracken \& Roth, 1989), suggests that on the whole they may show stronger preferences for diverse clothing meanings.

\section{Methodology}

\subsection{Procedure}

The study is based on a cross-sectional survey. Structured face-to-face interviews were conducted in the Czech Republic by an international market research agency. A quota sampling procedure based on five quota controls (administrative region, locality size, gender, age, and education) was used. Random selection procedures were performed in all but the final stage of participants' selection. The interviews were conducted at 195 sampling points and 1,065 filled-in questionnaires were obtained. The response rate (total interviews as a percentage of total interviews plus refusals) was $60 \%$. Six questionnaires were discarded due to missing data. In total 1,059 usable questionnaires were retained for data analysis. The questionnaire was prepared in English and validated by back and parallel (from a third language) translation procedures (Craig \& Douglas, 2000). A few changes were made to ensure translation equivalence and good comprehension. A pilot test was run with 15 respondents, which led to minor changes in the wording of a few questions. 
Respondents were between 18 and 55 years of age. The upper age limit was set because symbolic/hedonic consumption considerations are generally of lesser importance to older consumers, as well as because on the whole older Czechs have lower incomes and their consumption tends to be focused on essentials. In the sample, $50.3 \%$ of the respondents were men and $49.7 \%$ women. Respondents' distribution according to age was: 18-24 age group (21.5\%), 25-34 age group (29.2\%), 35-44 age group (20.4\%), and 45-55 age group (28.9\%). The sample's marital status was: single $-28.7 \%$, married $-60.9 \%$, divorced $-8.7 \%$, and widowed $-1.7 \%$. The respondents were distributed in terms of their education level as follows: primary and lower secondary education $-32.6 \%$, upper secondary education $56.9 \%$, and university education $-10.5 \%$.

\subsection{Measures}

\subsubsection{Independent and mediator variables, and gender covariate}

The independent and interdependent self-construals were measured using Singelis' updated scale (Singelis et al., 1999). Small modifications of a few items were done to make the inventory more comprehensible by the respondents. Preferences for clothing's self-symbolic, status-symbolic and hedonic meanings were measured partly with items adapted from Mittal's (1988) expressiveness scale. Three items capture preference for self-expressive meaning, two items tap into hedonic experiences, and six items measure preference for status meaning. A three-item scale based on Bearden et al.'s (1989) items, which tap into referents' identification through consumption, was used to capture preference for affiliation symbolism. Respondents' answers were measured on a five-point Likert scale: 1 (strongly disagree) to 5 (strongly agree).

Gender was entered in the analysis as a dummy variable: $0=$ male and $1=$ female gender. 


\subsubsection{Dependent variables}

Actual purchase behavior was measured using three single-item scales. Frequency of visits to clothing shops to see whether they have received something new was recorded on an eightpoint scale: 1 "Several times a week" to 8 "Once in more than a year" (reverse-coded). Frequency of clothing purchases for oneself was recorded on an eight-point scale: 1 "Once a week" to 8 "Once in more than three years" (reverse-coded). Finally, clothing spending was captured by the question: "Would you tell me approximately how much money have you spent on clothes for yourself since the beginning of this year?"

\subsubsection{Scales' reliability and validity}

The psychometric properties of the independent and mediator scales were checked with CFA. The fit of the measurement model was satisfactory: $\mathrm{chi}^{2} / \mathrm{df}=4.051, \mathrm{GFI}=.939, \mathrm{CFI}=.929$, and RMSEA = .054. After deleting items with loadings below 0.50 , three (four) items from the independent (interdependent) self measure were retained for further analysis. All twofactor models showed significantly improved fit relative to the one-factor models.

Nonetheless, the self-expressive and hedonic factors were highly correlated (0.92) and thus merged in the consequent analysis, which is in line with Mittal (1988). One item from the affiliation measure cross-loaded above 0.3 on the status meaning measure and subsequently was deleted. In the final model all factor loadings were above 0.5 and significant at the .001 level. Besides, all but one construct reliability were above 0.7 : independent self (0.79), interdependent self (0.77), preference for self-expressive/hedonic meanings (0.87), preference for status meaning $(0.83)$, and preference for affiliation meaning $(0.57)$. The last reliability statistic became relatively low after deleting the cross-loading item (dropped from 0.65 ). Such a figure is not uncommon when its estimation is based on two items only. As a rule of thumb, within SEM a construct has to have at least three indicators to avoid potential model 
identification problems. In our analysis retaining only two indicators of the affiliation meaning construct did not cause an identification issue, as the construct had significant relationships with other constructs: the independent self, frequency of clothing purchases, and money spent on clothing (see Hair et al. 2006, p. 792). Given that preference for affiliation meaning is an important aspect of symbolic consumption, that its reliability score is above 0.5 , as well as the lack of identification problems during model estimation, we decided to retain this construct for further analysis. Nonetheless, some caution needs to be exercised when interpreting the study findings relating to preference for clothing affiliation symbolism. The average variance extracted (AVE) statistics for the independent self and preference for self-expressive/hedonic meanings were above 0.5 ( 0.56 and 0.58 , respectively), whereas for the interdependent self and preferences for status and affiliation meanings were $0.46,0.45$, and 0.40, respectively (see Fornell \& Larcker, 1981). The latter AVE values are not considerably below the 0.5 threshold, argued by some to be quite conservative and difficult to attain by many studies (e.g. Hatcher, 1994, p. 331). Additionally, all AVE statistics were higher than the square of the correlations between any two latent constructs. Hence, support for the convergent and discriminant validity of the constructs was found (Hair, Black, Babin, Anderson, \& Tatham, 2006). Constructs' means, standard deviations, and Pearson correlations are presented in Table 1.

[Table 1 here]

\section{Study results}

The Structural Equation Model including all hypothesized effects (see Figure 1), as well as the remaining paths for which no hypotheses were raised, was estimated using AMOS 21. To test the mediating role of preferences for self-expressive/hedonic and status meanings, a bootstrap method was used (Hayes, 2009; Zhao et al., 2010; Rucker et al., 2011). 
Specifically, 1,000 bootstrap samples with bias-corrected confidence intervals set at $95 \%$ were used to assess the significance of the effects (both hypothesized and unanticipated) of the independent and interdependent self-construals. All mediation tests were two-tailed. The fit of the model was satisfactory: $\mathrm{chi}^{2} / \mathrm{df}=4.664, \mathrm{GFI}=.924, \mathrm{CFI}=.908, \mathrm{RMSEA}=.059$. The standardized regression coefficients are provided in Table 2.

[Table 2 here]

H1 posits that more independent consumers show a stronger preference for the selfexpressive/hedonic meanings of clothing and that such preference leads to more frequent visits to clothing shops, more frequent purchases, and more money spent on shopping. Indeed, the independent self had a significant positive effect on preference for selfexpressive/hedonic meanings of clothing $(\beta=0.192, p<.01)$. However, at odds with prior expectation, preference for self-expressive/hedonic meanings did not have a significant effect on frequency of visits to clothing shops $(\beta=0.054, p=.39)$, frequency of clothing purchases $(\beta=-0.003, p=.99)$, and money spent on clothing $(\beta=-0.063, p=.33)$. In order to test the hypothesized mediated effects of the independent self through preference for selfexpressive/hedonic meanings, due to multiple mediators in our model the paths of this selfconstrual to the other two types of preferences for symbolic meanings were deleted. In this mediation model, the three indirect effects of the independent self-construal were not significant: frequency of visits to clothing shops $\left(I_{\text {stand. }}=0.006, p=.24\right)$; frequency of clothing purchases $\left(I_{\text {stand. }}=0.000, p=.91\right)$; money spent on clothing $\left(I_{\text {stand. }}=-0.007, p=.22\right)$. Further analysis revealed that the lack of support for H1 was mainly due to suppression caused by the significant positive correlation between preferences for self-expressive/hedonic and status meanings. This link is logical given that rarity, high price, and aesthetic properties 
of up-market goods make them rather suitable for expressing diverse aspects of one's self; not surprisingly, its estimation resulted in improved model fit. After deleting the covariance between these two constructs and estimating the indirect effect of the independent self through preference for self-expressive meaning, two of the three hypothesized indirect effects of the independent self were confirmed: frequency of visits to clothing shops $\left(I_{\text {stand. }}=0.026\right.$, $p<.01)$; frequency of clothing purchases $\left(I_{\text {stand. }}=0.017, p<.05\right)$.

According to $\mathrm{H} 2$, the independent self has a positive effect on preference for status meaning of clothing, which on its part has a positive effect on frequency of visits to clothing shops, frequency of clothing purchases, and money spent on clothing. Consistent with this notion, the independent self had a significant positive effect on preference for status symbolism $(\beta=0.175, p<.01)$, and the latter had a significant positive effect on frequency of visits to clothing shops $(\beta=0.445, p<.01)$, frequency of clothing purchases $(\beta=0.471, p<$ $.01)$, and money spent on clothing $(\beta=0.539, p<.01)$. The mediation tests, which followed the same approach as for $\mathrm{H} 1$, confirmed the hypothesized indirect effects of the independent self on all three aspects of actual purchase behavior: frequency of visits to clothing shops $\left(I_{\text {stand. }}=0.047, p<.05\right)$; frequency of clothing purchases $\left(I_{\text {stand. }}=0.052, p<.05\right)$, and money spent on clothing $\left(I_{\text {stand. }}=0.059, p<.05\right)$. Thus, $\mathrm{H} 2$ is fully supported. In this mediation model, the independent self had significant direct effects on frequency of visits to clothing shops $(\beta=-0.145, p<.01)$ and frequency of clothing purchases $(\beta=-0.12, p<.01)$, and a non-significant direct effect on money spent on clothing $(\beta=0.024, p=.56)$. This evidence suggests the presence of competitive mediation on frequency of visits to clothing shops and frequency of clothing purchases, and indirect-only mediation on money spent on clothing (see Zhao et al. 2010). However, in line with Rucker et al.'s (2011) argument about the potential problems of using terms such as 'partial' or 'full' mediation (e.g. evidence of full 
mediation can preclude the search for other potent mediators on the studied relationships), these two terms for mediation effects will not be used in the discussion that follows below.

Regarding the relationship between the interdependent self and preference for status meaning, the full model estimates indicated that this self-construal had a non-significant effect $(\beta=-0.014, p=.73)$. However, in the mediation model, where the paths between the interdependent self and preferences for self-expressive/hedonic and affiliation meanings were deleted, this effect of the interdependent self became significant $(\beta=-0.231, p<.01)$. The indirect effects' estimates of the mediation model indicated that the interdependent self had a significant negative influence on actual purchase behavior through preference for status meaning: frequency of visits to clothing shops $\left(I_{\text {stand. }}=-0.104, p<.01\right)$; frequency of clothing purchases $\left(I_{\text {stand. }}=-0.111, p<.01\right)$; money spent on clothing $\left(I_{\text {stand. }}=-0.127, p<.01\right)$. In addition, the direct effect of the interdependent self on frequency of clothing purchases was significant $(\beta=0.111, p<.05)$, but not on frequency of visits to clothing shops $(\beta=0.068, p$ $=.14)$ and money spent on clothing $(\beta=0.052, p=.26)$.

According to $\mathrm{H} 3$, the interdependent self has a positive effect on preference for affiliation meaning of clothing. Although the sign of the regression coefficient was in the hypothesized direction, it was not significant $(\beta=.081, p=.33)$. Hence, H3 was not supported. In an exploratory fashion, this study found a consistent pattern of negative effects of preference for clothing affiliation symbolism on frequency of visits to clothing shops $(\beta=-0.029, p=.42)$, frequency of clothing purchases $(\beta=-0.098, p<.05)$, and money spent on clothing $(\beta=$ $0.090, p<.05)$. The mediation model estimates revealed that the indirect effects of the interdependent self through affiliation meaning on all three dependent variables were not significant: frequency of visits to clothing shops $\left(I_{\text {stand. }}=-0.003, p=.24\right)$; frequency of clothing purchases $\left(I_{\text {stand. }}=-0.010, p=.09\right)$; money spent on clothing $\left(I_{\text {stand. }}=-0.009, p=\right.$ .10). These results indicate a lack of mediation on the part of preference for affiliation 
symbolism. However, two other significant mediation effects of preference for affiliation meaning were found in an additional exploratory mediation analysis, namely, on the effects of the independent self on frequency of clothing purchases $\left(I_{\text {stand. }}=0.029, p<.01\right)$ and money spent on clothing $\left(I_{\text {stand. }}=0.026, p<.05\right)$. Besides, the direct effect of the independent self on frequency of clothing purchases was negative and significant $(\beta=-0.119, p<.01)$, whereas on money spent on clothing was not significant $(\beta=-0.001, p=.98)$.

Regarding the effects of the gender covariate, as expected female consumers were more interdependent $(\beta=0.102, p<.05)$, less independent $(\beta=-0.073, p<.05)$, showed stronger preferences for self-expressive/hedonic $(\beta=0.152, p<.01)$ and status meanings $(\beta=0.154, p$ $<.01)$, visited more frequently clothing shops to see the new arrivals $(\beta=0.374, p<.01)$, and made more frequent clothing purchases $(\beta=0.213, p<.01)$ than their male counterparts. However, gender did not have a significant effect on preference for affiliation meaning $(\beta=-$ $0.068, p=.08)$, as well as on money spent on clothing $(\beta=-0.009, p=.78)$.

\section{Discussion}

This study explores the mechanisms of influence of the independent and interdependent selfconstruals on actual purchase behavior of clothing artifacts. The conceptual model considers the mediating role of preferences for self-expressive/hedonic and status meanings on the effects of the independent and interdependent self-construals on frequency of visits to clothing shops, frequency of clothing purchases, and money spent on clothing. The findings indicate that consumers with a dominant independent self-construal make a greater use of the self and status-symbolic and hedonic resources of clothing artifacts in the construction, expression, and enhancement of their unique identities. Besides, status and differentiation (i.e. avoiding clothes already in possession of important others) are the main drivers of their more frequent visits to clothing shops to see the new arrivals and to make purchases. The fact 
that most effects (both direct and indirect) of the independent self-construal are significant suggests that this type of consumers have well-defined individual and shopping goals, know what they would like to achieve with their purchases and instrumentally use them to reach desired end-states. This finding also underscores the high potential of the independent selfconstrual as a market segmentation variable.

As to consumers with a dominant interdependent self-construal, unexpectedly, they appear not to be interested in the affiliation meaning of clothing, and the latter does not mediate this self-construal's effects on actual purchase behavior. Having said this, the relatively weak reliability of the preference for affiliation symbolism scale might have some impact on this unanticipated finding. In addition, interdependents tend to shun status conveying clothing artifacts and, consequently, they are less active clothing consumers. This finding, together with the one for the independent consumers, underscores the high importance of status preferences in the consumption sphere. Interestingly, interdependents' clothing acquisitions are found here to be motivated to some extent by self-expression considerations. What is more, all but one direct effects of this self-construal are not significant. These findings together suggest that interdependent individuals are less active consumers and thus constitute a less attractive market segment.

Our findings also indicate that the different meanings interact with each other, with preference for clothing status symbolism permeating consumer preferences for self/hedonic and affiliation meanings.

\subsection{Independent and interdependent self-construals, preference for self-expressive and} hedonic meanings, and actual purchase behavior

Consistent with Markus and Kitayama's self-construals theory, the thesis about the positivity of one's independent self and the need for its self-expression, as well as previous research 
(e.g. Millan \& Reynolds, 2011), this study found that independent consumers tend to draw on clothing self-expressive imagery, as well on its potential to engender inner enjoyment. Additionally, in line with prior expectation derived mainly from the variety seeking (e.g. Herrmann \& Heitmann, 2006; Kim \& Drolet, 2003) and hedonic shopping literature (e.g. Millan \& Howard, 2007), preference for self-expressive and hedonic meanings of clothing has significant positive effects on frequency of visits to clothing shops to see the new arrivals and frequency of clothing purchases, although not on the amount of money spent on clothing. However, these significant effects become suppressed after controlling for the shared variance between preference for self-expression/hedonism and preference for status symbolism. This study's results indicate that the process of identity construction, expression and enhancement through consumption is also motivated by a desire to distance oneself from others' clothing choices by deliberately avoiding the attire worn by those others, no matter how close or important they may be.

A positive relationship that emerged in the analysis, but was not anticipated, concerns the interdependent self-construal and preference for self-expressive and hedonic clothing. Given their main focus on others rather than on oneself, why would interdependents be interested in clothing which expresses their identity, is compatible with the image they have of themselves, and engenders positive feelings? Although a similar finding is reported by Lee and Kacen (2000), this outcome is somewhat unanticipated. There are a few possible explanations. To begin with, given the modern societies' appreciation of individuality, for image management purposes interdependents may also desire to show some degree of uniqueness through their clothing choices. For them, the projection of such socially attractive image may be instrumental for group acceptance and approval. Next, interdependents may view their clothes, no matter how plain or modest they might be, as an expression of who they are and how they feel. Plainer clothing styles are a potent means for expression of thrift, 
frugality, and modesty values, which appear to be held in high regard by individuals with dominant interdependent self-construals (see Oishi, et al., 1998). Finally, interdependents' self-expression through clothing consumption may also be fuelled by past suppression of their individuality manifestation, which could be due to reasons such as lack of freedom of choice and access to value-expressive goods. The latter is particularly pertinent to this study's respondents, who under the socialist system experienced shortages of goods, including limited clothing assortment. Given the suppression of individuality under communist rule, including its expression through consumption, the new market realities now offer the freedom of choice that interdependent consumers desire to express themselves via clothing artifacts. What is more, the proliferation of Western style advertising in the Czech media space after 1989 (see Millan \& Mittal, 2010), typically portraying attractive ways of life and identities embedded in individualist Western cultural representations, feeds an admiration and a desire for emulation without too much thought and adequate integration into existing self-schemas (see Clark, III., Micken, \& Hart, 2002; Ger \& Belk, 1996).

\subsection{Independent and interdependent self-construals, preference for status meaning, and} actual purchase behavior

This research found that independent individuals show a stronger preference for status clothing. This finding provides support for the notion that independents tend to use status brands to satisfy their needs for uniqueness/distinction and personal achievement, as well as to gain more independence through achieved higher status. Also, as expected, consumer preference for status meaning results in more frequent shopping trips, more frequent purchases, and more money spent on clothing. Hence, consumers with a dominant independent self-construal tend to be more interested in the status symbolism of clothing, and this interest has a downstream effect on all studied actual purchase phenomena. 
As to the effect of the interdependent self-construal on preference for clothing status symbolism, this study found a significant negative relationship. This finding provides support for the arguments in the literature, according to which interdependents' need for harmonious relationships undisrupted by challenges to the existing status quo, coupled with their values of thrift, frugality, modesty and 'following the middle way', as well as with deeply rooted habits of utilitarian consumption, will lead to a lack of or a negative interest in status consumption. What is more, aversion to status markers seems to be an important factor that curbs their clothing shopping behavior.

\subsection{Interdependent self-construal and preference for affiliation meaning}

Counter to prior expectation derived from Markus and Kitayama’s (1991) self-construal theory and empirical evidence (e.g. Lee \& Kacen, 2000), this study found that interdependent individuals are indifferent to the affiliation symbolism of clothing. A likely explanation relates to the generally poor choice of clothing under socialism, which resulted in forced conformity in dress, and the radical changes in the market landscape after the introduction of market reforms in 1989, which provided the symbolic resources to break away from the socialist 'aesthetics of sameness' (Betts, 2000, p. 754). Now consumers have the opportunity to 'take revenge' for the imposed conformity and simplicity in their dress prior to 1989 (see Young, 2007). Related to this finding, preference for affiliation meaning did not mediate the relationships of the interdependent self-construal with the studied purchase behavior phenomena.

Another interesting but unanticipated finding is that a stronger preference for affiliation meaning tends to lead to weaker clothing-related consumption practices in terms of less frequent clothing purchases and less money spent on clothing. These effects suggest that 
seeking affiliation through clothing is likely to be driven by prevention rather than promotion strategies.

Finally, the confirmed hypothesized effects indicate the usefulness of the theories underlying the development of this study's model for explaining consumers' symbolic and hedonic preferences and actual clothing consumption in general, and in the context of the Czech Republic in particular. The national-cultural specifics for explaining some of the study's results indicate that they can provide additional insights into the researched phenomena and, therefore, should not be ignored.

\section{Managerial and research implications}

The study's findings have some managerial implications. Specifically, they underscore the usefulness of the independent and interdependent self-construals for explaining actual clothing consumption and for segmenting consumer markets. Independent consumers appear to be an attractive segment for status, self-expressive and hedonically appealing clothing artifacts. Hence, advertising stimuli employing independence, distinctiveness, personal status, individual achievement, and self-enhancement themes are likely to be particularly effective among this type of consumers. In their efforts to create and/or reinforce distinctive brand images, marketers need to focus on symbolic brand attributes such as reputable brand name, fashionable styles, esteemed country-of-origin, and premium prices particularly for status brands, as well as the self and status-symbolic and hedonic benefits they can deliver to their users. Within the retail environment, marketers need to pay particular attention to store design and atmospherics, as well as to service quality. More frequent introduction of new merchandise and the creation of a vibrant and varying store environment are likely to engender novel and positive in-store experiences, appealing to consumers with a dominant independent self-construal, and thus to motivate more frequent store visits and possibly 
purchases. This recommendation is particularly relevant for more individualist societies, where consumers with dominant independent self-construals constitute a sizable market.

As far as interdependent consumers are concerned, this study's findings indicate that they tend to be less active consumers, at least as far as clothing consumption is concerned. The finding that preference for status symbolism mediates the effect of the interdependent selfconstrual indicates that attempts to raise status consciousness among interdependent consumers in a group context may have some potential to stimulate clothing purchases. For example, marketing communications emphasizing the enhancement of one's in-group reputation, warm-hearted acceptance and high appreciation are likely to strike a cord with the interdependents. As self-expression emerged as a motivator of their clothing choices, adverts emphasizing self-expressive themes that are pertinent to this type of consumers and their shared value priorities may attract their attention and create positive brand attitudes. Continuing small scale in-store promotions could be used to stimulate interest and to act as a draw to the shops, which could possibly result in more frequent visits and purchases. Important others are a source of informational and normative social influences on interdependents' decision-making and actual purchases, and the former are likely to accompany the latter during a shopping trip. Thus, sales efforts can be focused on both the buyers and their companions. On the whole, marketers would need to allocate more marketing efforts and resources should they wish to attract the attention and win the custom of this consumer segment. This advice is more pertinent to collectivist societies, where the majority of consumers have dominant interdependent self-construals.

The results of this study suggest some possible directions for future research. To start with, as no previous study of which we are aware has considered consumer preferences for symbolic and hedonic meanings as mediators of the effects of the independent and interdependent self-construals on actual purchase behavior, more research is needed to test 
further the validity of the study's findings. Second, the link between the interdependent selfconstrual and preference for clothing affiliation symbolism appears to be more complex than initially anticipated. The non-confirmed effect of the interdependent self-construal on this symbolic meaning preference needs to be further examined with a more reliable measure of the latter construct. Third, in view of the competing theoretical explanations for and divergent evidence on the relationship between the interdependent self-construal and preference for status goods, additional research could establish whether this relationship holds for other status goods and in other cultural contexts. Fourth, the inconsistencies between collectivist values and the motivational underpinning of self-expressive consumer behavior, and the significant positive effect of the interdependent self-construal on preference for selfexpressive and hedonic meanings of clothing discovered here, indicate the need for further research to unpack this relationship. Fifth, the finding that self-expressive and hedonic tendencies did not result in more money spent on clothing (and which was counter to our hypothesis) needs to be explored in different cultural contexts (e.g. notably individualist settings, notably collectivist, and a mixture of both), which might also be characterized by different shopping environments, such as more leisure/entertainment oriented vs. more utilitarian/task oriented ones. And finally, as the way the independent and interdependent self-construals interact with actual purchase behavior has important managerial implications, additional studies on the significance of this dual self-construal in explaining actual consumption of other product categories are warranted.

The authors wish to thank the editor-in-chief and the anonymous reviewers, whose constructive comments contributed to enhancing the quality of the manuscript. 


\section{References}

Aaker, J. L. (1999). The malleable self: The role of self-expression in persuasion. Journal of Marketing Research, 36(1), 45-57.

Aaker, J. L., \& Lee, A. Y. (2001). "I" Seek Pleasures and "We" Avoid Pains: The Role of Self-Regulatory Goals in Information Processing and Persuasion. Journal of Consumer Research, 28(1), 33-49.

Aaker, J. L., \& Schmitt, B. (2001). Culture-Dependent Assimilation and Differentiation of the Self: Preferences for Consumption Symbols in the United States and China. Journal of Cross-Cultural Psychology, 32(5), 561-576.

Agrawal, N., \& Maheswaran, D. (2005). The Effects of Self-Construal and Commitment on Persuasion. Journal of Consumer Research, 31(4), 841-849.

Arnold, M. J., \& Reynolds, K. E. (2003). Hedonic shopping motivations. Journal of Retailing, 79(2), 77-95.

Auty, S., \& Elliott, R. (1998). Fashion Involvement, Self-Monitoring and the Meaning of Brands. Journal of Product \& Brand Management, 7(2), 109-123.

Bagozzi, R. P., Wong, N., Abe, S., \& Bergami, M. (2000). Cultural and Situational Contingencies and the Theory of Reasoned Action: Application to Fast Food Restaurant Consumption. Journal of Consumer Psychology, 9(2), 97-106.

Banim, M., Green, E., \& Guy, A. (2001). Introduction. In A. Guy, E. Green \& M. Banim (Eds.), Through the Wardrobe: Women's Relationships with Their Clothes (pp. 1-18). Oxford: Berg.

Baron, R. M., \& Kenny, D. A. (1986). Moderator-Mediator Variables Distinction in Social Psychological Research: Conceptual, Strategic, and Statistical Considerations. Journal of Personality and Social Psychology, 51(6), 1173-1182.

Bearden, W. O., Money, R. B., \& Nevins, J. L. (2006). Multidimensional versus unidimensional measures in assessing national culture values: The Hofstede VSM 94 example. Journal of Business Research, 59(2), 195-203.

Bearden, W. O., Netemeyer, R. G., \& Teel, J. E. (1989). Measurement of Consumer Susceptibility to Interpersonal Influence. Journal of Consumer Research, 15(4), 473-481.

Beaudoin, P., Lachance, M. J., \& Robitaille, J. (2003). Fashion Innovativeness, Fashion Diffusion and Brand Sensitivity among Adolescents. Journal of Fashion Marketing and Management, 7(1), 23-30.

Belk, R. W. (1988). Possessions and the Extended Self. Journal of Consumer Research, 15(2), 139-168.

Betts, P. (2000). The Twilight of the Idols: East German Memory and Material Culture. The Journal of Modern History, 72(3), 731-765.

Brewer, M. B., \& Gardner, W. (1996). Who Is This "We"? Levels of Collective Identity and Self Representation. Journal of Personality and Social Psychology, 71(1), 83-93.

Briley, D. A. (2009). Cultural influence on consumer motivation: A dynamic view. From the Selected Works of Donnel A Briley, Retrieved March 7, 2012, from http://works.bepress.com/briely/15.

Carr, H. L., \& Vignoles, V. L. (2011). Keeping up with the Joneses: Status projection as symbolic self-completion. European Journal of Social Psychology, 41(4), 518-527.

Chao, A., \& Schor, J. B. (1998). Empirical Tests of Status Consumption: Evidence from Women's Cosmetics. Journal of Economic Psychology, 19, 107-131.

Chen-Yu, J. H., \& Seock, Y.-K. (2002). Adolescents' Clothing Purchase Motivations, Information Sources, and Store Selection Criteria: A Comparison of Male/Female and Impulse/Nonimpulse Shoppers. Family and Consumer Sciences Research Journal, 31(1), 50-77. 
Chinese Culture Connection. (1987). Chinese Values and the Search for Culture-Free Dimensions of Culture. Journal of Cross-Cultural Psychology, 18, 143-146.

Clark, I., III., Micken, K. S., \& Hart, H. S. (2002). Symbols for Sale ... at Least for Now: Symbolic Consumption in Transition Economies. Advances in Consumer Research, 29, 25-30.

Clark, R. A., Zboja, J. J., \& Goldsmith, R. E. (2007). Status Consumption and Role-Relaxed Consumption: A Tale of Two Retail Consumers. Journal of Retailing and Consumer Services, 14(1), 45-59.

Coskuner, G., \& Sandikci, O. (2004). New Clothing: Meanings and Practices. Advances in Consumer Research, 31, 285-290.

Cox, J., \& Dittmar, H. (1995). The functions of clothes and clothing (dis)satisfaction: A gender analysis among British students. Journal of Consumer Policy, 18(2), 237-265.

Craig, C. S., \& Douglas, S. P. (2000). International Marketing Research (2 ed.). Chichester, West Sussex: Wiley \& Sons.

Crane, D. (2000). Fashion and Its Social Agendas: Class, Gender, and Identity in Clothing. Chicago: The University of Chicago Press.

Cross, S. E., \& Madson, L. (1997). Models of the self: Self-construals and gender. Psychological Bulletin, 122(1), 5-37.

Csikszentmihalyi, M., \& Rochberg-Halton, E. (1981). The Meaning of Things: Domestic Symbols and the Self: Cambridge: Cambridge University Press.

De Mooij, M. (2010). Global marketing and advertising: Understanding cultural paradoxes. Thousand Oaks, CA: Sage.

Dittmar, H. (1992). The Social Psychology of Material Possessions: To Have Is To Be. Hemel Hempstead: Harvester Wheatsheaf.

Dubois, B., \& Duquesne, P. (1993). The Market for Luxury Goods: Income versus Culture. European Journal of Marketing, 27(1), 35-44.

Dutta-Bergman, M. J., \& Wells, W. D. (2002). The Values and Lifestyles of Idiocentrics and Allocentrics in an Individualist Culture: A Descriptive Approach. Journal of Consumer Psychology, 12(3), 231-242.

Dutton, M. R. (1998). Streetlife China: Cambridge University Press.

Elliott, R. (1997). Existential Consumption and Irrational Desire. European Journal of Marketing, 31(3/4), 285-296.

Elliott, R., \& Wattanasuwan, K. (1998). Brands as Symbolic Resources for the Construction of Identity. International Journal of Advertising, 17(2), 131-144.

Fornell, C., \& Larcker, D. F. (1981). Evaluating Structural Equation Models with Unobservable Variables and Measurement Error. Journal of Marketing Research, 18(1), 39-50.

Gao, G. (1996). Self and Others: A Chinese Perspective on Interpersonal Relationships. In W.

B. Gudykunst, S. Ting-Toomey \& T. Nishida (Eds.), Communication in personal relationships across cultures (pp. 81-101): Sage.

Ger, G., \& Belk, R. W. (1996). I'd Like to Buy the World a Coke: Consumptionscapes of the "Less Affluent World". Journal of Consumer Policy, 19, 271-304.

Giddens, A. (1992). Modernity and Self-Identity: Self and Society and the Late Modern Age. Guy, A., \& Banim, M. (2000). Personal Collections: Women's clothing use and identity. Journal of Gender Studies, 9(3), 313-327.

Hair, J. F., Black, W. C., Babin, B. J., Anderson, R. E., \& Tatham, R. L. (2006). Multivariate Data Analysis (6 ed.). Upper Saddle River, NJ: Pearson/Prentice Hall.

Hayes, Andrew F. (2009). Beyond Baron and Kenny: Statistical Mediation Analysis in the New Millennium. Communication Monographs, 76(4), 408-420. 
Hatcher, L. (1994). A step-by-step approach to using the SAS system for factor analysis and structural equation modeling. Cary, NC: SAS Institute.

Heine, S., Lehman, D., Markus, H. R., \& Kitayama, S. (1999). Is There a Universal Need for Positive Self-Regard? Psychological Review, 106, 766-794.

Herrmann, A., \& Heitmann, M. (2006). Providing More or Providing Less?: Accounting for Cultural Differences in Consumers' Preference for Variety. International Marketing Review, 23(1), 7-24.

Hirschman, E. C., \& LaBarbera, P. A. (1990). Dimensions of Possession Importance. Psychology \& Marketing, 7(3), 215-233.

Hofstede, G. H. (1980). Culture's Consequences: International Differences in Work-Related Values. Beverly Hills, CA: Sage.

Holbrook, M. B., \& Hirschman, E. C. (1982). The Experiential Aspects of Consumption: Consumer Fantasies, Feelings, and Fun. Journal of Consumer Research, 9(2), 132-140.

Howlett, N., Pine, K., Orakçioglu, I., \& Fletcher, B. (2013). The influence of clothing on first impressions: Rapid and positive responses to minor changes in male attire. Journal of Fashion Marketing and Management, 17(1), 38-48.

Kaiser, S. B., Freeman, C. M., \& Chandler, J. L. (1993). Favorite clothes and gendered subjectivities: Multiple readings. Studies in Symbolic Interaction, 15, 27-50.

Kastanakis, M. N., \& Balabanis, G. (2012). Between the mass and the class: Antecedents of the "bandwagon" luxury consumption behavior. Journal of Business Research, 65(10), 1399-1407.

Kim, H. S., \& Drolet, A. (2003). Choice and Self-Expression: A Cultural Analysis of Variety-Seeking. Journal of Personality and Social Psychology, 85(2), 373-382.

Kleine, R. E., III., Kleine, S. S., \& Kernan, J. B. (1993). Mundane Consumption and the Self: a Social-Identity Perspective. Journal of Consumer Psychology, 2(3), 209-235.

Kleine, S. S., Kleine, R. E., III., \& Allen, C. T. (1995). How Is a Possession "Me" or "Not Me"? Characterizing Types and an Antecedent of Material Possession Attachment. Journal of Consumer Research, 22(3), 327-343.

Kwan, V. S. Y., Bond, M. H., \& Singelis, T. M. (1997). Pancultural Explanations for Life Satisfaction: Adding Relationship Harmony to Self-Esteem. Journal of Personality and Social Psychology, 73(5), 1038-1051.

Layard, R. (1980). Human Satisfactions and Public Policy. The Economic Journal, 90(360), 737-750.

Lee, F., \& Tiedens, L. Z. (2001). Is it lonely at the top: The independence and interdependence of power holders. Research in Organizational Behavior, 23, 43-91.

Lee, J. A. (2000). Adapting Triandis's Model of Subjective Culture and Social Behavior Relations to Consumer Behavior. Journal of Consumer Psychology, 9(2), 117-126.

Lee, J. A., \& Kacen, J. J. (2000). The Relationship Between Independent and Interdependent Self-Concepts and Reasons for Purchase. Journal of Euromarketing, 8(1), 83-99.

Lim, E. A. C., \& Ang, S. H. (2008). Hedonic vs. Utilitarian Consumption: A Cross-Cultural Perspective Based on Cultural Conditioning. Journal of Business Research, 61(3), 225232.

Markus, H., \& Kitayama, S. (1991). Culture and the Self: Implications for Cognition, Emotion and Motivation. Psychological Review, 98(2), 224-253.

Mason, R. (1992). Modeling the Demand for Status Goods. In F. W. Rudmin \& M. Richins (Eds.), Meaning, Measure, and Morality of Materialism (pp. 88-95). Provo, UT: Association for Consumer Research.

McCracken, G. D., \& Roth, V. J. (1989). Does Clothing Have a Code? Empirical Findings and Theoretical Implications in the Study of Clothing as a Means of Communication. International Journal of Research in Marketing, 6, 13-33. 
Microsoft. (2009). Lovers of Luxury II: Luxury Consumption in Asia \& Europe and the Role of Digital Media, Retrieved October 7, 2013, from www.webtech.us/research/Lovers\%20of\%20Luxury\%20II.PDF.

Millan, E. S., \& Howard, E. (2007). Shopping for Pleasure? Shopping Experiences of Hungarian Consumers. International Journal of Retail \& Distribution Management, 35(6), 474-487.

Millan, E. S., \& Mittal, B. (2010). Advertising's New Audiences. Journal of Advertising, 39(3), 81-98.

Millan, E. S., \& Reynolds, J. (2011). Independent and Interdependent Self-Views and Their Influence on Clothing Consumption. International Journal of Retail \& Distribution Management, 39(3), 162-182.

Mintel. (2010). Youth Fashion - UK - December 2010. London: Mintel Oxygen.

Mintel. (2011). Clothing - Western Europe (selected countries) - a snapshot. London: Mintel Intelligence.

Mittal, B. (1988). The Role of Affective Choice Mode in the Consumer Purchase of Expressive Products. Journal of Economic Psychology, 9, 499-524.

Noble, C. H., \& Walker, B. A. (1997). Exploring the Relationships among Liminal Transitions, Symbolic Consumption, and the Extended Self. Psychology \& Marketing, 14(1), 29-47.

Noth, W. (1988). The Language of Commodities: Groundwork for a Semiotics of Consumer Goods. International Journal of Research in Marketing, 4, 173-186.

O'Cass, A. (2004). Fashion Clothing Consumption: Antecedents and Consequences of Fashion Clothing Involvement. European Journal of Marketing, 38(7), 869-882.

O'Cass, A., \& McEwen, H. (2006). Exploring Consumer Status and Conspicuous Consumption. Journal of Consumer Behavior, 4(1), 25-39.

Oishi, S., Schimmack, U., Diener, E., \& Suh, E. M. (1998). The Measurement of Values and Individualism-Collectivism. Personality and Social Psychology Bulletin, 24(11), 11771189.

Palan, K. M. (2001). Gender Identity in Consumer Behavior Research: A Literature Review and Research Agenda. Academy of Marketing Science Review, 2001(10), 1-24.

Peluchette, J., Karl, K., \& Rust, K. (2006). Dressing to Impress: Beliefs and Attitudes Regarding Workplace Attire. Journal of Business \& Psychology, 21(1), 45-63.

Piaceniti, M., \& Mailer, G. (2004). Symbolic Consumption in Teenagers' Clothing Choices. Journal of Consumer Behavior, 3(3), 251-262.

Richins, M. L. (1994a). Valuing Things: The Public and Private Meanings of Possessions. Journal of Consumer Research, 21(3), 504-521.

Richins, M. L. (1994b). Special Possessions and the Expression of Material Values. Journal of Consumer Research, 21(3), 522-533.

Rogers, E. M. (2003). Diffusion of Innovations (5 ed.). London: Free Press.

Rose, S., \& Dhandayudham, A. (2014). Towards an understanding of Internet-based problem shopping behavior: The concept of online shopping addiction and its proposed predictors. Journal of Behavioral Addictions, 1-7. doi: 10.1556/JBA.3.2014.003.

Roth, M. (1995). The Effects of Culture and Socioeconomics on the Performance of Global Brand Image Strategies. Journal of Marketing Research, 32(2), 163-175.

Rucker, Derek D., Preacher, Kristopher J., Tormala, Zakary L., \& Petty, Richard E. (2011). Mediation Analysis in Social Psychology: Current Practices and New Recommendations. Social and Personality Psychology Compass, 5/6, 359-371.

Schwartz, S. H. (1994). Beyond Individualism/Collectivism: New Cultural Dimensions of Values. In U. Kim, H. C. Triandis, C. Kagitcibasi, S.-C. Choi \& G. Yoon (Eds.), 
Individualism and Collectivism: Theory, Method, and Applications (pp. 85-119). Thousand Oaks, CA: Sage Publications.

Schwartz, S. H., \& Bardi, A. (2001). Value Hierarchies Across Cultures. Journal of CrossCultural Psychology, 32(3), 268-290.

Schwarz, B., \& Wong, V. (2006). Cover Story: Money Talks, Retrieved February 5, 2013, from http://www.amcham-shanghai.org/NR/rdonlyres/FCCD3DCF-18BB-4705-9C8DC677B764ACE1/2572/01_cover_story.pdf.

Sheth, J. N., Newman, B. I., \& Gross, B. L. (1991). Why We Buy What We Buy: A Theory of Consumption Values. Journal of Business Research, 22(2), 159-170.

Singelis, T. M. (1994). The Measurement of Independent and Interdependent Self-Construals. Personality and Social Psychology Bulletin, 20(5), 580-591.

Singelis, T. M., Bond, M. H., Sharkey, W. F., \& Lai, C. S. Y. (1999). Unpackaging Culture's Influence on Self-Esteem and Embarrassability: The Role of Self-Construals. Journal of Cross Cultural Psychology, 30(3), 315-341.

Singelis, T. M., \& Brown, W. J. (1995). Culture, Self, and Collectivist Communication: Linking Culture to Individual Behavior. Human Communication Research, 21(3), 354389.

Sirgy, M. J. (1982). Self-Concept in Consumer Behavior: A Critical Review. Journal of Consumer Research, 9(3), 287-300.

Sterling, G. (2012). Survey: Mobile Will Loom Large In Holiday Shopping. Retrieved from http://marketingland.com/survey-mobile-will-loom-large-in-holiday-shopping-24965. Accessed 2014, February 07.

Tepper, K., \& Hoyle, R. H. (1996). Latent Variable Models of Need for Uniqueness. Multivariate Behavioral Research, 31(4), 467-494.

Thompson, C. J., \& Haytko, D. L. (1997). Speaking of Fashion: Consumers' Uses of Fashion Discourses and the Appropriation of Countervailing Cultural Meanings. Journal of Consumer Research, 24(1), 15-28.

Trafimow, D., Triandis, H. C., \& Goto, S. G. (1991). Some Tests of the Distinction between the Private Self and the Collective Self. Journal of Personality and Social Psychology, 60(5), 649-655.

Triandis, H. C. (1993). Collectivism and Individualism as Cultural Syndromes. CrossCultural Research, 27(3/4), 155-181.

Veblen, T. (1899). The Theory of the Leisure Class: An Economic Study of Institutions. London: Unwin Books, reprinted New York: Dover Publications, 1994.

Wang, C. L., Bristol, T., Mowen, J. C., \& Chakraborty, G. (2000). Alternative Modes of SelfConstrual: Dimensions of Connectedness-Separateness and Advertising Appeals to the Cultural and Gender-Specific Self. Journal of Consumer Psychology, 9(2), 107-115.

Wang, C. L., \& Mowen, J. C. (1997). The Separateness-Connectedness Self-Schema: Scale Development and Application to Message Construction. Psychology \& Marketing, 14(2), 185-207.

Wong, N. Y., \& Ahuvia, A. C. (1998). Personal Taste and Family Face: Luxury Consumption in Confucian and Western Societies. Psychology \& Marketing, 15(5), 423-441.

Young, R. (2007). Style \& Design: Luxury no Longer Means Loud in Russia, International Herald Tribune, November 22, 2007.

Zhao, Xinshu, Lynch Jr., John G., \& Chen, Qimei (2010). Reconsidering Baron and Kenny: Myths and Truths about Mediation Analysis. Journal of Consumer Research, 37(2), 197 206. 


\section{Figure 1}

Conceptual framework of the relationships among the independent and interdependent selfconstruals, consumer preferences for clothing's symbolic and hedonic meanings, and actual purchase behavior

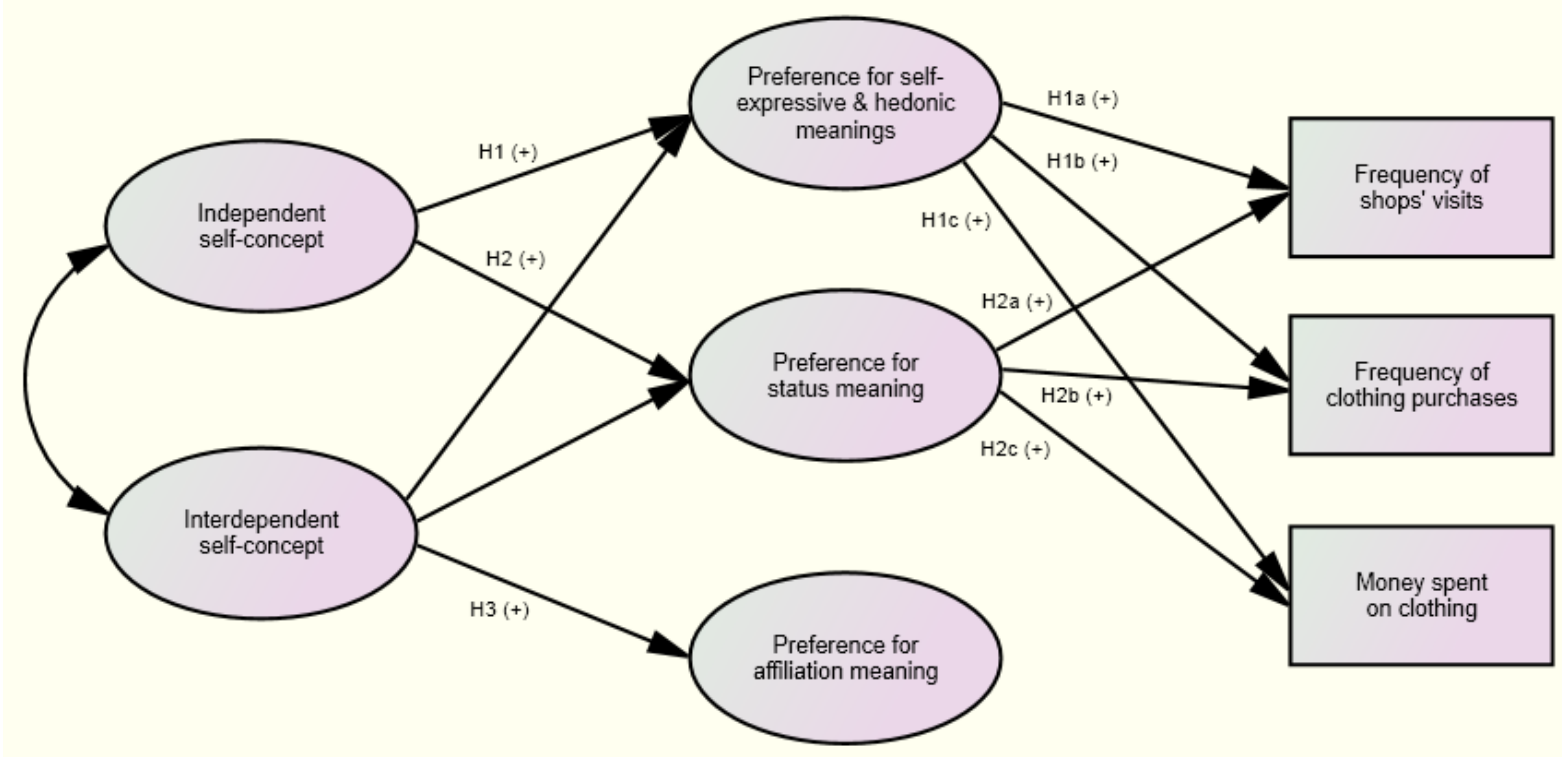

Note: For clarity of presentation, the following covariances are not included in Figure 1: preferences for self-expressive/hedonic and status meanings; frequency of shops' visits and clothing purchases; and frequency of clothing purchases and money spent on clothing. 
Table 1

Means, standard deviations and correlations among constructs

\begin{tabular}{|c|c|c|c|c|c|c|c|c|c|c|c|}
\hline & Constructs & Mean & S.D. & 1 & 2 & 3 & 4 & 5 & 6 & 7 & 8 \\
\hline 1. & Independent self & 4.088 & 0.662 & 1 & & & & & & & \\
\hline 2. & Interdependent self & 4.030 & 0.563 & $.298 * *$ & 1 & & & & & & \\
\hline 3. & $\begin{array}{l}\text { Preference for self- } \\
\text { expressive/hedonic } \\
\text { meanings }\end{array}$ & 4.006 & 0.639 & $.284 * *$ & $.359 * *$ & 1 & & & & & \\
\hline 4. & $\begin{array}{l}\text { Preference for status } \\
\text { meaning }\end{array}$ & 2.776 & 0.839 & $.126 * *$ & .033 & $.479 * *$ & 1 & & & & \\
\hline 5. & $\begin{array}{l}\text { Preference for } \\
\text { affiliation meaning }\end{array}$ & 2.521 & 0.782 & $-.116^{* *}$ & -.030 & $.141^{* *}$ & $.445 * *$ & 1 & & & \\
\hline 6. & $\begin{array}{l}\text { Frequency of shops' } \\
\text { visits to see new } \\
\text { arrivals }\end{array}$ & $\begin{array}{l}4.760 \\
\text { (once a } \\
\text { month) }\end{array}$ & 1.613 & -.044 & $.084 *$ & $.329 * *$ & $.451 * *$ & $.205 * *$ & 1 & & \\
\hline 7. & $\begin{array}{l}\text { Frequency of } \\
\text { clothing purchases }\end{array}$ & $\begin{array}{c}5.797 \\
\text { (once in } 3 \\
\text { months) }\end{array}$ & 0.979 & .012 & $.092 *$ & $.296^{* *}$ & $.420 * *$ & $119 * *$ & $.667 * *$ & 1 & \\
\hline 8. & $\begin{array}{l}\text { Money spent on } \\
\text { clothing (Kč) }\end{array}$ & $\begin{array}{c}3.540 \\
(6,001- \\
9,000)\end{array}$ & 1.814 & $.102 *$ & .041 & $.258 * *$ & $.438 * *$ & $128 * *$ & $.378 * *$ & $.464 * *$ & 1 \\
\hline
\end{tabular}


Table 2

Bootstrap estimates of the effects of the independent/interdependent self-construals and consumer preferences for symbolic and hedonic meanings of clothing on actual purchase behavior (Beta coefficients and significance)

\begin{tabular}{|c|c|c|c|c|}
\hline Estimated Path & & & Beta & $\boldsymbol{P}$ \\
\hline Independent self & $\rightarrow$ & $\begin{array}{l}\text { Preference for self- } \\
\text { expressive/hedonic meanings }\end{array}$ & 0.192 & .002 \\
\hline Interdependent self & $\rightarrow$ & $\begin{array}{l}\text { Preference for self- } \\
\text { expressive/hedonic meanings }\end{array}$ & 0.374 & .003 \\
\hline Independent self & $\rightarrow$ & Preference for status meaning & 0.175 & .001 \\
\hline Interdependent self & $\rightarrow$ & Preference for status meaning & -0.014 & .734 \\
\hline Independent self & $\rightarrow$ & $\begin{array}{l}\text { Preference for affiliation } \\
\text { meaning }\end{array}$ & -0.230 & .029 \\
\hline Interdependent self & $\rightarrow$ & $\begin{array}{l}\text { Preference for affiliation } \\
\text { meaning }\end{array}$ & 0.081 & .327 \\
\hline $\begin{array}{l}\text { Preference for self- } \\
\text { expressive/hedonic meanings }\end{array}$ & $\rightarrow$ & $\begin{array}{l}\text { Frequency of shops' visits to see } \\
\text { new arrivals }\end{array}$ & 0.054 & .387 \\
\hline $\begin{array}{l}\text { Preference for self- } \\
\text { expressive/hedonic meanings }\end{array}$ & $\rightarrow$ & Frequency of clothing purchases & -0.003 & .986 \\
\hline $\begin{array}{l}\text { Preference for self- } \\
\text { expressive/hedonic meanings }\end{array}$ & $\rightarrow$ & Money spent on clothing & -0.063 & .325 \\
\hline $\begin{array}{l}\text { Preference for status } \\
\text { meaning }\end{array}$ & $\rightarrow$ & $\begin{array}{l}\text { Frequency of shops' visits to see } \\
\text { new arrivals }\end{array}$ & 0.445 & .002 \\
\hline $\begin{array}{l}\text { Preference for status } \\
\text { meaning }\end{array}$ & $\rightarrow$ & Frequency of clothing purchases & 0.471 & .003 \\
\hline $\begin{array}{l}\text { Preference for status } \\
\text { meaning }\end{array}$ & $\rightarrow$ & Money spent on clothing & 0.539 & .002 \\
\hline $\begin{array}{l}\text { Preference for affiliation } \\
\text { meaning }\end{array}$ & $\rightarrow$ & $\begin{array}{l}\text { Frequency of shops' visits to see } \\
\text { new arrivals }\end{array}$ & -0.029 & .420 \\
\hline $\begin{array}{l}\text { Preference for affiliation } \\
\text { meaning }\end{array}$ & $\rightarrow$ & Frequency of clothing purchases & -0.098 & .017 \\
\hline $\begin{array}{l}\text { Preference for affiliation } \\
\text { meaning }\end{array}$ & $\rightarrow$ & Money spent on clothing & -0.090 & .024 \\
\hline Independent self & $\rightarrow$ & $\begin{array}{l}\text { Frequency of shops' visits to see } \\
\text { new arrivals }\end{array}$ & -0.147 & .002 \\
\hline Independent self & $\rightarrow$ & Frequency of clothing purchases & -0.119 & .006 \\
\hline Independent self & $\rightarrow$ & Money spent on clothing & -0.002 & .974 \\
\hline Interdependent self & $\rightarrow$ & $\begin{array}{l}\text { Frequency of shops' visits to see } \\
\text { new arrivals }\end{array}$ & 0.060 & .229 \\
\hline Interdependent self & $\rightarrow$ & Frequency of clothing purchases & 0.112 & .049 \\
\hline Interdependent self & $\rightarrow$ & Money spent on clothing & 0.059 & .274 \\
\hline Gender (cov) & $\rightarrow$ & Independent self & -0.073 & .028 \\
\hline Gender (cov) & $\rightarrow$ & Interdependent self & 0.102 & .012 \\
\hline Gender (cov) & $\rightarrow$ & $\begin{array}{l}\text { Preference for self- } \\
\text { expressive/hedonic meanings }\end{array}$ & 0.152 & .002 \\
\hline Gender (cov) & $\rightarrow$ & Preference for status meaning & 0.154 & .002 \\
\hline Gender (cov) & $\rightarrow$ & $\begin{array}{l}\text { Preference for affiliation } \\
\text { meaning }\end{array}$ & -0.068 & .084 \\
\hline Gender (cov) & $\rightarrow$ & $\begin{array}{l}\text { Frequency of shops' visits to see } \\
\text { new arrivals }\end{array}$ & 0.374 & .001 \\
\hline Gender (cov) & $\rightarrow$ & Frequency of clothing purchases & 0.213 & .001 \\
\hline Gender (cov) & $\rightarrow$ & Money spent on clothing & -0.009 & .780 \\
\hline
\end{tabular}

